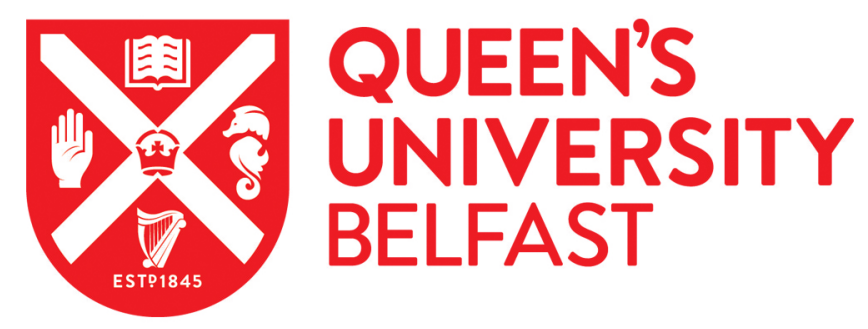

\title{
Application of a Damping Torque Analysis index for coordinated tuning of stabilisers in a large power grid
}

Cai, H., Littler, T., Huang, J. H., \& Xie, Z. J. (2014). Application of a Damping Torque Analysis index for coordinated tuning of stabilisers in a large power grid. In Proceedings of the IEEE Power Engineering Society General Meeting (PESGM 2014) Institute of Electrical and Electronics Engineers Inc..

https://doi.org/10.1109/PESGM.2014.6939213

Published in:

Proceedings of the IEEE Power Engineering Society General Meeting (PESGM 2014)

Document Version:

Peer reviewed version

Queen's University Belfast - Research Portal:

Link to publication record in Queen's University Belfast Research Portal

Publisher rights

Copyright 2014 IEEE.

This work is made available online in accordance with the publisher's policies. Please refer to any applicable terms of use of the publisher.

\section{General rights}

Copyright for the publications made accessible via the Queen's University Belfast Research Portal is retained by the author(s) and / or other copyright owners and it is a condition of accessing these publications that users recognise and abide by the legal requirements associated with these rights.

Take down policy

The Research Portal is Queen's institutional repository that provides access to Queen's research output. Every effort has been made to ensure that content in the Research Portal does not infringe any person's rights, or applicable UK laws. If you discover content in the Research Portal that you believe breaches copyright or violates any law, please contact openaccess@qub.ac.uk. 


\title{
Application of a Damping Torque Analysis Index for Coordinated Tuning of Stabilisers in a Large Power Grid
}

\author{
H. Cai ${ }^{1}$, T. Littler ${ }^{1}$, J.H. Huang ${ }^{2}$, Z.J.Xie ${ }^{2}$ \\ ${ }^{1}$ School of Electronics, Electrical Engineering and Computer Science, \\ Queen's University Belfast, UK \\ ${ }^{2}$ State Grid, Jiangsu Economic Research Institute, Nanjing, China \\ caihui300@hotmail.com
}

\begin{abstract}
This paper considers the coordinated tuning of stabilisers attached to the primary control loop of a Synchronous Generator (SG), Doubly Fed Induction Generator (DFIG) and Energy Storage System (ESS) in a large-scale electric power grid. The indices obtained from a Damping Torque Analysis (DTA) method are used to evaluate the impact of different stabilisers subject to a range of low-frequency oscillations. According to the DTA Indices, a coordinated stabiliser-tuning strategy is proposed. Selected stabilisers are tuned effectively to dampen target oscillations without rendering eigenvalue drift. The damping ratios of interarea oscillation modes and local modes can be increased beyond nominal values, without time-intensive and redundant-stabiliser adjustment.
\end{abstract}

Index Terms-Stabiliser, coordinated tuning, DTA Index, lowfrequency oscillation, damping ratio.

\section{INTRODUCTION}

In this paper, low frequency oscillations are defined as electromechanical perturbations which occur on a large-scale power system in the range $0.1-2 \mathrm{~Hz}$, primarily as a consequence of interconnection. Small disturbances, for example small-variations in load and generation, short-term three-phase short circuit or tripping of a transmission line, can trigger and accentuate trigger these oscillations. Once started, they will continue for a while and then disappear, or continuously grow to cause system collapse. In the future, the power system will be more widely interconnected and complicated with uncertainty in generated output from largescale renewable energy sources. Due to the severe influences induced by unstable or weakly-damped oscillations, smallsignal stability of future power systems requires immediate attention [1][2].

There are two essential theoretical methods to analyse power system low-frequency oscillation damping: 1) model (or eigenvalue) analysis method by calculation [3][4]; and 2) damping torque analysis (DTA) using physical insight [5]. The model analysis method can not give a direct and effective description of the physical mechanism, while DTA cannot be applied easily in a multi-unit power system.

In [8-10], DTA has been extended for application in a multi-machine power system and demonstrated to be basically equivalent to modal analysis. The DTA index denotes the impact from a reconstructed feedback signal of a stabiliser to the selected oscillation loop and is a summary in two loops. Firstly the stabiliser supplies damping torque to the electromechanical loop of every synchronous generator. Then, the delivered damping torque is rendered from a specified oscillation mode by multiplying the eigenvalue sensitivity of the corresponding generator. DTA indices for a power system stabiliser (PSS), flexible AC transmission system (FACTS)based stabiliser, static synchronous compensator (STATCOM)based stabiliser and energy storage system (ESS)-based stabiliser are obtained in [11-16] according to the PhillipsHeffron model. They can be used to choose location [17], evaluate contribution [9], adjust parameter [18] and set the feedback signals of the stabilisers [8].

In large power systems, with $n$ machines, there exists $n-1$ oscillation modes which include interarea and local modes are [1]. In current systems, several types of stabilisers can be added and adjusted to improve the damping of the system, such as PSS, HVDC stabiliser [19], FACTS-based stabiliser [20] and doubly fed induction generator (DFIG)-based stabilisers [21]. The coordination and tuning of various stabilisers to effectively increase the damping ratios of oscillation modes, without eigenvalue drift with respect to one another, are discussed in this paper.

The organisation of this paper is as follows: in Section II, small-signal analysis of the large power grid is presented. DTA indices for PSS, ESS-based stabiliser and DFIG-based stabiliser are briefly described and obtained in Section III. Based on the DTA Indices, a hierarchical and coordinated stabiliser-tuning strategy is proposed. In Section IV, the effectiveness of the proposed tuning strategy is verified by the eigenvalue calculations in the system. Finally, brief remarks on the studies are presented indicating that: a PSS improves damping of oscillation modes in which the corresponding synchronous generator strongly participates; an ESS-based stabiliser is appropriate to suppress tie-line power oscillations where it is connected; a DFIG-based stabiliser best smoothes output power oscillations in an associated outlet line. In the proposed strategy, only certain selected stabilisers need to be tuned and low-frequency oscillations can be restrained within an acceptable time.

\section{SMALl SignAl ANALYSIS OF LARGE POWER GRID}

\section{A. System Modelling}

A small-signal stability analysis system, which refers to a Chinese provincial power grid under peak load condition of 
Year 2012, is established in this paper. The simulated system is mainly composed of a $1000 \mathrm{kV}, 500 \mathrm{kV}$ and $220 \mathrm{kV}$ level alternating current (AC) network with several hundred synchronous generators (SGs) and several thousand 1.5 MW DFIG units, distributed in 13 wind farms. For analysis, the system has been simplified to 66 equivalent SGs, 604 buses and 13 equivalent DFIGs, while retaining the predominant oscillation modes of the system [22]. A detailed model is adopted for equivalent generators with consideration of the speed governors, automatic voltage regulators (AVR), as well as the PSS units installed in 15 equivalent SGs [23]. In terms of the 65,000 MW active output power from the SGs, $1900 \mathrm{MW}$ is generated by DFIGs which occupy $2.84 \%$ of the total generation. A novel control strategy for the DFIG in [24] has been used. The schematic configuration diagram of the power grid is shown in Figure 1. All equivalent SGs and DFIGs are distributed in 15 areas. The generator labels ending with ' $G$ ' denote equivalent SGs and ' $W$ ' signifying equivalent DFIGs.

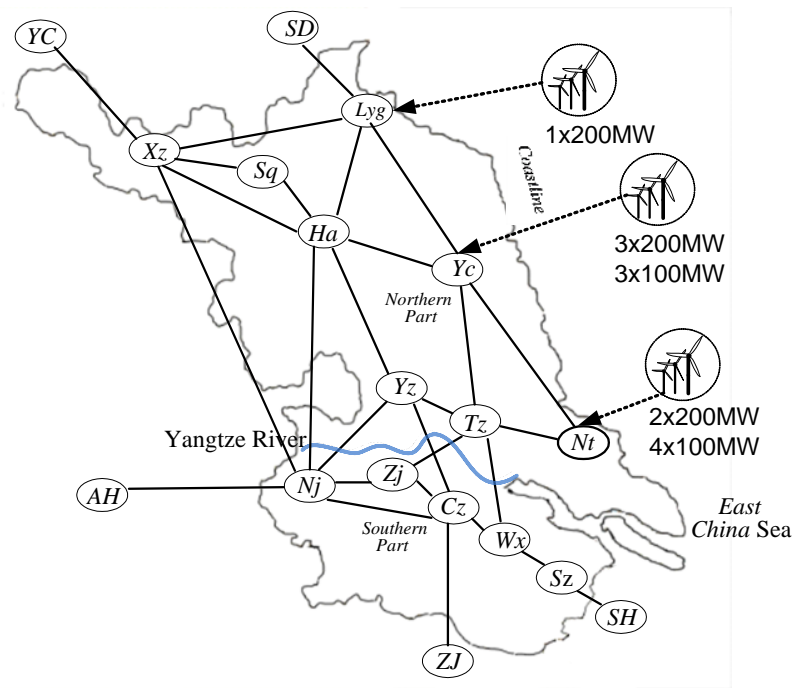

Fig. 1. Schematic configuration diagram of the power system model.

\section{B. Small Signal Analysis of the Power Grid}

Inside the power grid, the SGs are mainly concentrated in the northern part of the system, in addition to the DFIGs, however load consumption is mostly populated in the southern region. In the system, approximately 11, $210 \mathrm{MW}$ of active power is transferred from the northern to the southern part using five $500 \mathrm{kV}$ and one $1000 \mathrm{kV}$ double-loop AC transmission lines across the Yangtze River. As a consequence of a heavy load burden and the long transmission distance, the suppression of power oscillations in these transmission lines is preferential and critical to maintain dynamic stability.

Besides oscillations in the north-south transmission lines, other oscillations exist in the tie-lines between the cities. The interarea electromechanical oscillation modes with frequency in the range of $0.1-1.0 \mathrm{~Hz}$ and damping ratio less than $5 \%$ are selected and listed in Table I. The weakly-damped oscillations in the connected lines can lead to the disconnection of subsystems.

\begin{tabular}{|l|l|l|}
\hline $\begin{array}{l}\text { Interarea } \\
\text { Mode }\end{array}$ & $\begin{array}{l}\text { Frequency } \\
(\mathrm{Hz})\end{array}$ & $\begin{array}{l}\text { Damping } \\
\text { ratio }\end{array}$ \\
\hline Mode 1 & 0.8035 & $2.62 \%$ \\
\hline Mode 2 & 0.9994 & $3.47 \%$ \\
\hline Mode 3 & 0.8646 & $3.93 \%$ \\
\hline
\end{tabular}

Mode 1 is related to the oscillations between the northern and southern parts. The equivalent SXZ_G, SPC3G, SKS_G (in $X z$ ), STW_G, SXH1G (in $L y g$ ) and SCJ_G (in $Y c$ ) oscillate against SLE_G, SWE_G (in $W x$ ), SHS1G, SHS2G, SSE_G, SWR_G, SHB1G (in $S z$ ), SQR3G (in $C z$ ), and SJK_G (in $Z j$ ). Nearly all of the cities in northern and southern parts are involved. All of the 15 listed equivalent SGs have PSSs installed.

Mode 2 is related to the oscillations between $X z$ and $L y g$. The equivalent SXZ_G (in $X z$ ) oscillates against STW_G, SXH1G and SXH2G (in Lyg).

Mode 3 is related to the oscillations between $S z, W x$, and $C z$. The equivalent SHS1G, SHS2G and SHB2G (in $S z$ ) oscillate against SQR3G (in $C z$ ) and SLE_G (in $W x$ ).

All the listed equivalent SGs participate in the corresponding oscillation modes with participation factors $>0.1$.

In the next section, a hierarchical coordinated stabilisertuning strategy based on a DTA index is proposed to increase the damping ratios of these listed modes beyond 5\%, and with the least adjustment.

\section{COORdinAted Stabiliser-Tuning STRATEGY}

Theoretically, a DTA index investigates the forward-path information from the reconstructed feedback signal of the stabiliser to the oscillation mode using the electromechanical oscillation loops of the generators on the basis of the PhillipsHeffron (P-H) model [17]. While the DTA index analysis is completed with the stabiliser in open-loop, direction for leftshifting the eigenvalue can be given. The precise pole assignment of the eigenvalue cannot be obtained.

With development of the phasor measurement unit (PMU), not only the rotor-speed of the PSS-installed generator, but also the remote generator equivalent can be used as the feedback signal of the PSS. While it is more economic and effective to use the rotor-speed signal of the PSS-installed generator as the feedback signal [9][10], in this paper the feedback signals for all PSSs are used.

\section{A. DTA Indices of PSSs related to the Interarea Oscillation Modes}

Table II lists DTA indices of PSSs related to the 3 listed interarea oscillation modes.

TABLE II. DTA INDICES OF PSSS RELATED TO INTERAREA OSCILLATION MODES

\begin{tabular}{|c|c|c|c|}
\hline $\begin{array}{c}\text { PSS-installed } \\
\text { Generator }\end{array}$ & $\begin{array}{c}\text { Oscillation } \\
\text { Mode 1 }\end{array}$ & $\begin{array}{c}\text { Oscillation } \\
\text { Mode 2 }\end{array}$ & $\begin{array}{c}\text { Oscillation } \\
\text { Mode 3 }\end{array}$ \\
\hline SXZ_G & 0.0010 & 0.0358 & 0.0000 \\
\hline SPC3G & 0.0008 & 0.0000 & 0.0000 \\
\hline SKS_G & 0.0012 & 0.0000 & 0.0000 \\
\hline STW_G & 0.0033 & 0.0102 & 0.0000 \\
\hline SXH1G & 0.0016 & 0.0064 & 0.0000 \\
\hline
\end{tabular}




\begin{tabular}{|c|c|c|c|}
\hline SCJ_G & 0.0006 & 0.0000 & 0.0000 \\
\hline SLE_G & 0.0018 & 0.0000 & 0.0104 \\
\hline SWE_G & 0.0013 & 0.0000 & 0.0000 \\
\hline SHS1G & 0.0016 & 0.0000 & 0.0157 \\
\hline SHS2G & 0.0019 & 0.0000 & 0.0138 \\
\hline SSE_G & 0.0007 & 0.0000 & 0.0000 \\
\hline SWR_G & 0.0004 & 0.0000 & 0.0000 \\
\hline SHB1G & 0.0010 & 0.0000 & 0.0000 \\
\hline SQR3G & 0.0014 & 0.0000 & 0.0042 \\
\hline SJK_G & 0.0005 & 0.0000 & 0.0000 \\
\hline
\end{tabular}

From Table II, it can be seen that:

For Mode 1, around 15 generators are involved. The DTA index of each single PSS is small, thus adjusting the control gains of a small number of PSSs cannot significantly increase the damping ratio. While Mode 1 is the key interarea mode in the system, the parameters of all PSSs need to be tuned.

For Mode 2, the DTA indices of the PSSs installed in SXZ_G, STW_G and SXH1G are significant, thus and all other PSSs ignore the impact to this oscillation mode. This means that adjusting the control gain of the PSSs installed in SXZ_G, STW_G and SXH1G can sufficiently increase the damping ratio.

For Mode 3, the DTA indices of the PSS installed in SLE_G, SHS1G and SHS2G are selected, while all other PSSs have a negligible impact on this oscillation mode. Adjusting the control gain of the PSSs installed in SLE_G, SHS1G and SHS2G can therefore increase the damping ratio beyond the satisfied value.

\section{B. DTA Indices of ESS-based Stabilisers related to the} Interarea Oscillation Modes

With advances in power electronics technology, large-scale application of ESS units is feasible. In principle, the application of ESS-based stabilisers in power systems can effectively provide extra damping for power system oscillations, with an ESS damping function achieved through active power modulation using exchange of active power directly between the ESS and the connected line [2].

In this paper, ESS-based stabilisers are installed in the candidate buses of the river-crossed transmission lines. Active power deviations of the ESS-connected lines are chosen as the feedback signals. DTA indices are obtained [15][16] and listed in Table III.

TABLE III. DTA INDICES OF ESS-BASED STABILISERS RELATED TO INTERAREA OSCILLATION MODES

\begin{tabular}{|c|c|c|c|}
\hline $\begin{array}{c}\text { ESS-installed } \\
\text { Bus }\end{array}$ & $\begin{array}{c}\text { Oscillation } \\
\text { Mode 1 }\end{array}$ & $\begin{array}{c}\text { Oscillation } \\
\text { Mode 2 }\end{array}$ & $\begin{array}{c}\text { Oscillation } \\
\text { Mode 3 }\end{array}$ \\
\hline SSC (in Nj) & 0.0351 & 0.0000 & 0.0000 \\
\hline SJD (in Yz) & 0.0287 & 0.0000 & 0.0000 \\
\hline STX (in Tz) & 0.0274 & 0.0000 & 0.0000 \\
\hline
\end{tabular}

From Table III, it can be seen that the ESS-based stabilisers installed in the terminal buses of the river-crossed transmission lines greatly affect the damping of the tie-line power oscillations related to Mode 1. Their impact to the other oscillation modes can be neglected.
C. DTA Indices of DFIG-based Stabilisers related to the Interarea Oscillation Modes

A DFIG is not only capable of providing a network with better voltage recovery and fault ride-through characteristics, but it can also considerably enhance network damping using an auxiliary power system stabiliser loop [25]. While the process to obtain the DTA index of a DFIG-based stabiliser is similar to that for PSSs and ESS-based stabilisers, it is not described in this paper. The active power deviation of the outlet lines are picked out as the feedback signals of DFIG-based stabilisers. The DTA indices are listed in Table IV.

TABLE IV. DTA INDICES OF DFIG-BASED STABILISERS RELATED TO INTERAREA OSCILLATION MODES

\begin{tabular}{|c|c|c|c|}
\hline DFIG & $\begin{array}{c}\text { Oscillation } \\
\text { Mode 1 }\end{array}$ & $\begin{array}{c}\text { Oscillation } \\
\text { Mode 2 }\end{array}$ & $\begin{array}{c}\text { Oscillation } \\
\text { Mode 3 }\end{array}$ \\
\hline DFW (in Yc) & 0.0000 & 0.0000 & 0.0000 \\
\hline BHW (in Yc) & 0.0001 & 0.0001 & 0.0001 \\
\hline SYW (in Yc) & 0.0000 & 0.0000 & 0.0000 \\
\hline DTW (in Yc) & 0.0000 & 0.0001 & 0.0000 \\
\hline GHW (in Yc) & 0.0001 & 0.0000 & 0.0002 \\
\hline XSW (in Yc) & 0.0000 & 0.0002 & 0.0000 \\
\hline GYW (in Lyg) & 0.0002 & 0.0000 & 0.0000 \\
\hline LHW (in Nt) & 0.0002 & 0.0002 & 0.0000 \\
\hline LLW (in Nt) & 0.0000 & 0.0000 & 0.0000 \\
\hline LYW (in Nt) & 0.0000 & 0.0000 & 0.0000 \\
\hline DYW (in Nt) & 0.0001 & 0.0001 & 0.0002 \\
\hline RDW (in Nt) & 0.0000 & 0.0000 & 0.0000 \\
\hline HQW (in Nt) & 0.0001 & 0.0000 & 0.0000 \\
\hline
\end{tabular}

From Table IV, it can be seen that the DFIG-based stabilisers cannot contribute extra damping to the three interarea oscillation modes, because of their low participation factors [26] and penetration levels. They can, however be used to suppress the power oscillations in the outlet lines.

\section{Proposed Coordinated Tuning Strategy for Stabilisers}

Using an optimisation method to coordinate the tuning of all the PSS parameters is an effective way to improve the damping of the three critical oscillation modes simultaneously [27]. But the optimal adjustment of PSSs for the interarea modes may possibly deteriorate local modes. In practice, the greater parameters involved in the optimisation function, the longer the time/cost required for iteration. So it is impractical to include all local oscillation modes.

From the previous listed DTA indices of the PSSs, ESSbased and DFIG-based stabilisers, it can be concluded that each stabiliser has an effective influence on particular oscillation modes. A PSS improves damping of oscillation modes in which the corresponding synchronous generator is strongly participates; an ESS-based stabiliser can suppress tieline power oscillation where it is connected; a DFIG-based stabiliser has no effective impact on interarea oscillation modes, but can be used to regulate and smooth power oscillations in an associated outlet line.

A coordinated tuning strategy for stabilisers is proposed based on the conclusion obtained from the DTA indices, as follows:

Step 1: Weakly-damped or unstable interarea oscillation modes in which a few synchronous generators strongly participate are resolved whereby the control gains of the PSSs with high DTA indices (related to the corresponding interarea 
modes) are tuned; and also by consideration of locally dominant modes. While the number of adjusted PSSs is limited, it is practical to resolve close interarea and local modes. The adjusted PSSs would therefore have a slight impact on other oscillation modes.

Step 2: After adjustment of PSSs, an ESS-based stabiliser is used to improve the damping of interarea oscillation modes, in which a number of PSSs need to be regulated by coordination. The ESS-based stabiliser is connected to the corresponding tie-line and used to directly regulate active power oscillation in the transmission line. While the ESS-based stabiliser ignores the impact on other modes, it can be installed and adjusted for a target oscillation mode independently.

Step 3: The damping ratios of all the interarea and local oscillation modes should be increased beyond a set (target) value, using the Steps $1 \& 2$. The DFIG-based stabiliser can then be simply tuned to smooth its output power with neglected impact on the interarea and local oscillation modes.

The proposed stabiliser-tuning strategy is demonstrated and verified by the eigenvalue calculations in the next section.

\section{CASE Study}

While the effectiveness of a DTA index has already been verified [8-18], in this section, eigenvalue calculations are used to demonstrate the effectiveness of the proposed stabiliser-tuning strategy.

The artificial fish swarm algorithm (AFSA), derived from modern control theory and widely used to solve the optimisation function, was used to coordinate the adjustment of PSS parameters. The eigenvalues are compared by using the proposed strategy and AFSA respectively to improve the damping ratio of the three interarea oscillation modes.

Adjusted stabilisers: Using the proposed method, the control gains of the PSSs installed in the SXZ_G, SHS1G and SHS2G are adjusted to increase the damping of Mode 2 and Mode 3 and an extra ESS with 100MW capacity is installed in SSC (in $N j)$. The stabiliser was designed and attached to the ESS [15][16][28]. According to the AFSA, all parameters of the PSSs in the system need to be adjusted.

Time cost: Using the proposed method, time is used as the cost parameter in the DTA index calculation, thus the determination is completed only once, under certain load flow condition. But according to the AFSA, an eigenvalue calculation should be obtained in each iteration. Hence the construction of a linear matrix for such a huge system is complicated and time-costly and as such, 15-20 iterations are required to get the optimal parameters.

Economic cost: Using the proposed method, an extra ESS is needed. The ESS could be a large-scale battery storage, pump storage or super-capacitor. When support is required by the system operator, an ESS can be grid-connected and used to suppress oscillations by exchanging active power with the grid. Although no extra equipment is needed for the AFSA, PSS adjustment, while benefitting interarea oscillation modes, may render deterioration of other oscillations among local generators.

Effects on interarea oscillation modes: Table $\mathrm{V}$ shows the comparison of eigenvalues related to the three interarea oscillation modes by using the proposed tuning strategy and AFSA.

TABLE V. COMPARISONS OF EIGENVALUES

\begin{tabular}{|c|c|c|c|c|}
\hline \multicolumn{2}{|c|}{ Oscillation Mode } & Mode 1 & Mode 2 & Mode 3 \\
\hline \multirow{2}{*}{$\begin{array}{c}\text { Initial } \\
\text { Condition }\end{array}$} & $\begin{array}{c}\text { Frequency } \\
(\mathrm{Hz})\end{array}$ & 0.8035 & 0.9994 & 0.8646 \\
\cline { 2 - 5 } & $\begin{array}{c}\text { Damping } \\
\text { Ratio }\end{array}$ & $2.62 \%$ & $3.47 \%$ & $3.93 \%$ \\
\hline $\begin{array}{c}\text { Proposed } \\
\text { Strategy }\end{array}$ & $\begin{array}{c}\text { Frequency } \\
(\mathrm{Hz})\end{array}$ & 0.8257 & 1.0375 & 0.8871 \\
\cline { 2 - 5 } & $\begin{array}{c}\text { Damping } \\
\text { Ratio }\end{array}$ & $7.21 \%$ & $7.13 \%$ & $7.18 \%$ \\
\hline AFSA & $\begin{array}{c}\text { Frequency } \\
(\mathrm{Hz})\end{array}$ & 0.8112 & 1.0301 & 0.8799 \\
\cline { 2 - 5 } & $\begin{array}{c}\text { Damping } \\
\text { Ratio }\end{array}$ & $7.14 \%$ & $6.02 \%$ & $5.75 \%$ \\
\hline
\end{tabular}

From Table V, it can be seen that,

(1) Using the proposed strategy, the same effect to Mode 1 can be achieved with AFSA.

(2) Because weight factors are used to classify the priorities of different optimisation objectives in AFSA, the tuning of PSSs is mainly used to increase the damping ratio of Mode 1 which is more critical to maintain power safety transmission between the northern and southern parts. The damping ratios of Mode 2 and Mode 3 with less-priority do not have such significant increments as in Mode 1.

With the proposed tuning strategy, selected PSSs can be adjusted for Mode 2 and Mode 3. An ESS-based stabiliser is installed and designed to improve the damping ratio of Mode 1, without leading to eigenvalue-drift of the other two modes. While the three oscillation modes can be regulated independently, their damping ratios can be increased to same satisfied set values.

(3) In this case, no DFIG-based stabiliser is required to adjust the three interarea oscillation modes.

The effectiveness of the proposed strategy based on the obtained DTA Index has been demonstrated and verified by the above eigenvalue calculation. The damping ratios of the three weakly-damped interarea oscillation modes are all effectively increased, without imposing eigenvalue-drift on the remaining modes.

\section{CONCLUSIONS}

In a large-scale, multi-regional interconnected power system grid - with bulk power transmitted over long distances - interarea low-frequency oscillations are often a prevalent problem. This paper describes a comprehensive, small-signal analysis of a real Chinese provincial power grid (in Year 2012) and explores a hierarchical control strategy for both PSS control and ESS-based stabilisers by means of a coordinated parameter adjustment using DTA indices. The objective of the work has been to restrain interarea oscillations on this grid (in Year 2012) for future growth.

From the work presented in this paper, it can be concluded that: 1) an ESS-based stabiliser can be used to suppress tie-line power oscillations; 2) a PSS improves the damping of oscillation modes in which a corresponding synchronous generator strongly participates; and 3) a DFIG-based stabiliser best smoothes output power oscillations in an associated outlet 
line. Using the proposed strategy, only a few stabilisers need to be tuned and all interarea oscillations can be suppressed within an acceptable timeframe. The feasibility of the proposed method has been demonstrated and verified by the eigenvalue calculations obtained from the Year 2012 power grid system model.

\section{ACKNOWLEDGMENT}

The authors would like to acknowledge the support of Queen's University of Belfast, UK in this work.

\section{REFERENCES}

[1] P. Kundur, Power System Stability and Control, The EPRI Power System Engineering Series, McGraw-Hill, 1994.

[2] W. Du, H.F. Wang, and R. Dunn, "Power System Oscillation Stability and Control by FACTS and ESS- A Survey", International Conference on Sustainable Power Generation and Supply, 2009, SUPERGEN '09, pp1-13, 2009.

[3] G. Rogers, "Demystifying Power System Oscillation" Computer Application in Power, IEEE, vol.9, no. 3, pp. 30-35,1996.

[4] G. Rogers, Power System Oscillation, Kluwer Academic Publishers, 2000.

[5] X.F. Wang, Z.L. Fang and Z.C. Du, Modern Power System Analysis, Science Press 2003 (in Chinese).

[6] P. Pourbeik and M.J. Gibbard, "Damping and synchronizing torques induced on generators by FACTS stabilisers in multi-machine power system", IEEE Transaction on Power Systems, vol. 11, issue 4, pp1920$1925,1996$.

[7] M.J. Gibbard, D.J. Vowles and P. Pourbeik, "Interactions between, and effectiveness of, power system stabilisers and FACTS device stabilisers in multi-machine system", IEEE Transactions on Power Systems, vol. 15 , issue. 2, 2000, pp748-755.

[8] H.F. Wang "Selection of Robust Installing Locations and Feedback Signals of FACTS-based Stabilisers in Multi-machine Power Systems" IEEE Transactions on Power Systems, vol.14,no. 2, pp. 569-574, May 1999.

[9] H.F. Wang, "The connections among the electric torque, residue, sensitivity, participation and partial multi-modal decomposition" '98, UKACC International Conference on Control, Conf. Publ. no.455, Sep. 1998.

[10] F.J. Swift and H.F. Wang "The connection between modal analysis and electric torque analysis in the studying the oscillation stability of multimachine power systems" Electrical Power \& Energy Systems, vol.19, no. 5, pp. 321-330, 1997.

[11] H.F. Wang and F.J. Swift, "Multiple stabiliser setting in multi-machine power systems by the phase compensation method", Int. J. of Electrical Power and Energy Systems, Vol. 20, No. 4, 1998, pp241-246.

[12] H.F. Wang, F.J. Swift and M. Li, "A unified model for the analysis of FACTS devices in damping power system oscillations part II: multimachine power system", IEEE Transactions on Power Delivery, vol. 13, issue 4, 1998, pp1355-1362.

[13] H.F. Wang, "A unified model for the analysis of FACTS devices in damping power system oscillations part III: unified power flow controller", IEEE Trans. Power Delivery, vol. 15, issue 3, pp978-983, 2000.

[14] H.F. Wang, "Phillps-Heffron model of power systems installed with STATCOM and applications", IEE Proc. Part C, Vol. 146, No. 5, pp521-527, 1999.

[15] W. Du, H.F. Wang, L.Y. Xiao and R. Dunn, "Phillips-Heffron model of power sysems installed with energy storage systems (ESS)", Proceedings of the $44^{\text {th }}$ International Universities Power Engineering Conference (UPEC), pp1-5, 2009.

[16] H.F. Li, W. Du, H.F. Wang and Y.X, Xiao, "Damping torque analysis of energy storage system control in a multi-mahcine power system", $2^{\text {nd }}$
IEEE PES International Conference and Exhibition on Innovative Smart Grid Technologies (ISGT Europe) 2011, pp1-8, 2011.

[17] H.F. Wang, F.J. Swift and M. Li. "Indices for selecting the best location of PSSs or FACTS-based stabilisers in multimachine power systems: A comparative study" IEE Proceedings Generation, Transmission and Distribution, vol.144, no. 2, pp. 155-159, Mar. 1997.

[18] H.F. Wang, M. Li and F.J. Swift, "FACTS-based stabiliser designed by the phase compensation method. I. Single-machine infinite-bus power systems. II. Multi-machine power systems", Fourth International Conference on APSCOM-97, vol. 2, pp638-649, 1997.

[19] X.M. Mao, Y. Zhang, L. Guan and X.C. Wu, "Coordinated Control of Interarea Oscillation in the China Southern Power Grid", IEEE Transaction on Power Systems, Vol. 21, No. 2, pp845-852, May 2006.

[20] L.J. Cai and I. Erlich, "Simultaneous Coordinated Tuning of PSS and FACTS Damping Controllers in Large Power Systems", IEEE Transactions on Power Systems, Vol. 20, No. 1, pp294-300, Feb. 2005.

[21] F.M. Hughes, O. Anaya-Lara, N. Jenkins and G. Strbac, "Control of DFIG-Based Wind Generation for Power Network Support", IEEE Transactions on Power Systems, Vol. 20, No. 4, pp1958-1966, November 2005.

[22] Y.X. Ni, S.S. Chen and B.L. Zhang, Power System Dynamic Theory and Analysis, Tsinghua University Press, 2002 (in Chinese).

[23] Y. Tang, G.Q. Bu, Y.H. Yin, J.X. Hou, X.H. Tao and X.L. Song, Manuel about PSD-BPA dynamic stability analysis Software, China Electrical Power Research Institute, March 2007 (in Chinese).

[24] S.Q. Bu, W. Du, H.F. Wang, Z. Chen, L.Y. Xiao and H.F. Li, "A Novel Control Strategy for the Doubly Fed Induction Generators to Improve Grid Fault Ride-Through Capability", IEEE PES ISGT EUROPE 2011, Manchester UK, December 2011

[25] F.M. Hughes, O. Anaya-Lara, N. Jenkins and G. Strbac, "A Power System Stabiliser for DFIG-Based Wind Generation", IEEE Transaction on Power Systems, Vol. 21, No. 2, pp763-772, May 2006.

[26] T. Knueppel, J.N. Nielsen, K.H. Jensen, A. Dixon and J. Oestergaard, "Small-signal stability of wind power system with full-load converter interfaced wind turbines", IET Renewable Power Generation, Vol. 6 , Issue 2, pp79-91, 2012.

[27] H. Cai, W. Du, H. F. Wang, H. F. Li, 'Applying the Artificial Fish Swarm Algorithm for the Co-ordinated Design of PSSs in a Real Largescale Power System', The 2nd ISGT Innovative Smart Grid Technologies Conference, Europe 2011, Manchester, UK.

[28] W. Du, H.F. Li, J. Cao, H.F. Wang, Y.X. Xiao, "Design of an energy storage system in a multi-machine power system", IET Conference on Renewable Power Generation (RPG 2011), pp1-6, 2011.

\section{BIOGRAPHIES}

H. Cai received the B.S. degree from the School of Electrical Engineering, Southeast University, P.R. China, and M.S. degree from RWTH Aachen University, Germany, in 2006 and 2009 respectively. He completed a Ph.D. degree in the electric power and energy research cluster, Queen's University, Belfast, UK in 2013.

His research interests are power stability analysis, renewable energy integration and charging/discharging management of electric vehicles.

Dr. T. Littler received the BEng (Hons) degree in Electronic Systems from the University of Ulster in 1991 and a Ph.D. and PGCHET from the Queen's University, Belfast in 1998 and 2002, respectively. He joined the School of Electronics, Electrical Engineering and Computer Science (EEECS) in 2001. Currently he is a Lecturer in the school.

His research interests include power systems, wind and renewable energy generation and integration, Smart Grid, power system analysis and protection, system stability, cyber-security, statistical and time-series methods and intelligent algorithms. 